\title{
Links between the Southern Annular Mode and the Atlantic Meridional Overturning Circulation in a Climate Model
}

\author{
Camille Marini, Claude Frankignoul, and Juliette Mignot \\ LOCEAN, Université Pierre et Marie Curie, Paris, France
}

(Manuscript received 15 December 2009, in final form 6 September 2010)

\begin{abstract}
The links between the atmospheric southern annular mode (SAM), the Southern Ocean, and the Atlantic meridional overturning circulation (AMOC) at interannual to multidecadal time scales are investigated in a 500-yr control integration of the L'Institut Pierre-Simon Laplace Coupled Model, version 4 (IPSL CM4) climate model. The Antarctic Circumpolar Current, as described by its transport through the Drake Passage, is well correlated with the SAM at the yearly time scale, reflecting that an intensification of the westerlies south of $45^{\circ} \mathrm{S}$ leads to its acceleration. Also in phase with a positive SAM, the global meridional overturning circulation is modified in the Southern Hemisphere, primarily reflecting a forced barotropic response. In the model, the AMOC and the SAM are linked at several time scales. An intensification of the AMOC lags a positive SAM by about $8 \mathrm{yr}$. This is due to a correlation between the SAM and the atmospheric circulation in the northern North Atlantic that reflects a symmetric ENSO influence on the two hemispheres, as well as an independent, delayed interhemispheric link driven by the SAM. Both effects lead to an intensification of the subpolar gyre and, by salinity advection, increased deep convection and a stronger AMOC. A slower oceanic link between the SAM and the AMOC is found at a multidecadal time scale. Salinity anomalies generated by the SAM enter the South Atlantic from the Drake Passage and, more importantly, the Indian Ocean; they propagate northward, eventually reaching the northern North Atlantic where, for a positive SAM, they decrease the vertical stratification and thus increase the AMOC.
\end{abstract}

\section{Introduction}

The Southern Ocean is a key component of the climate system. Its circulation is dominated by the Antarctic Circumpolar Current (ACC) that transports about 125$135 \mathrm{~Sv}\left(1 \mathrm{~Sv} \equiv 10^{6} \mathrm{~m}^{3} \mathrm{~s}^{-1}\right)$ of water around Antarctica (Cunningham et al. 2003) and links the Atlantic, Indian, and Pacific Oceans, redistributing water masses from one basin to another, thus playing a fundamental role in the global oceanic circulation. The ACC is largely driven by the strong southern westerlies, primarily reflecting the balance between surface wind stress and bottom stress due to the pressure gradient across topographic features on the ocean floor (Munk and Palmen 1951; Olbers et al. 2004). It may also be influenced by the wind stress curl (Stommel 1957) and buoyancy forcing (Gnanadesikan and Hallberg 2000). The atmospheric variability in the

Corresponding author address: Camille Marini, LOCEAN, Université Pierre et Marie Curie, 4 place Jussieu, 75252 Paris CEDEX 05, France.

E-mail: camille.marini@locean-ipsl.upmc.fr
Southern Hemisphere is strongly dominated by the southern annular mode (SAM; Thompson and Wallace 2000). A positive phase of the SAM corresponds to an intensification and southward shift of the westerlies. Using low-resolution coupled ocean-atmosphere models, several studies (e.g., Hall and Visbeck 2002; Sen Gupta and England 2006) show that the intensification of the westerlies creates an anomalous northward Ekman drift. Through mass continuity, this enhances the upwelling around Antarctica, leading to a large vertical tilt of the isopycnals in the Southern Ocean and thus an increase of the ACC transport.

The southern ocean-atmosphere system may play a driving role in the global meridional overturning circulation (MOC). Based on sensitivity studies with an ocean circulation model forced by annual mean boundary conditions at the surface, Toggweiler and Samuels (1995) found that stronger winds blowing in the latitude band of the Drake Passage increase deep-water formation in the North Atlantic and the deep outflow through the South Atlantic. Indeed, a stronger zonal wind stress increases the northward Ekman transport around Antarctica. As 
a net meridional geostrophic flow is only possible in the presence of zonal boundaries, they argued that the return flow must pass below the sill of the Drake Passage (at about $2500 \mathrm{~m}$ ), where topography allows a zonal pressure gradient. Such a deep-water flow can only be formed where the stratification is weak enough, namely in the northern North Atlantic. Sijp and England (2009) examined the influence of the position of the Southern Hemisphere westerlies on the global MOC in a global ocean-ice circulation model coupled to a simplified atmosphere. The latitude of the zero-wind stress curl was shown to control both the amount of relatively fresh water coming from the Drake Passage into the Atlantic basin and the inflow of salty water coming from the Indian Ocean through the Agulhas leakage, so that a northward shift of the westerlies reduced the Atlantic MOC (AMOC) but enhanced the thermohaline sinking in the North Pacific; the opposite occurred for a southward shift. Toggweiler and Russell (2008) argued that the predicted increase and poleward shift of the westerlies in the twenty-first century should bring more deep water from the Southern Ocean interior to the surface, leading to more sinking and a stronger AMOC. This would oppose the weakening of the AMOC predicted by climate models in a warmer climate (Gregory et al. 2005) so that it is important to better understand the relation between the Southern Hemisphere winds and the AMOC. All these studies were based on coarse-resolution ocean models and focused on the equilibrium response to different wind configurations; the transient behavior was only briefly discussed in Sijp and England (2009), who showed that the AMOC adjustment was taking at least $30 \mathrm{yr}$.

Meredith et al. (2004) found observational evidence that the seasonality of the transport through Drake Passage is well correlated with that of the SAM, but Böning et al. (2008) detected no increase in the tilt of the isopycnals between the 1960s and recent years, as would be expected from the positive trend in the SAM during recent decades, or as simulated by coarse-resolution models. They thus concluded that the ACC transport and the meridional overturning in the Southern Ocean were insensitive to decadal changes in the wind stress, and they argued that mesoscale eddies play an integral role in stabilizing the oceanic response. Although it may seem debatable to solely link the ACC transport to the SAM in the changing environment of the last few decades, this suggests that mesoscale eddies need to be resolved to study the Southern Ocean response to changing winds. Screen et al. (2009) investigated the response of the Southern Ocean temperature to the SAM in a forced oceanic model at resolutions ranging from coarse (with a Gent and McWilliams parameterization; Gent and McWilliams 1990) to eddy resolving. The fast response was similar, but the high-resolution version showed an increase in the Southern Ocean mesoscale eddy kinetic energy 2-3 yr after a positive SAM, which resulted in a warming of the upper layers south of the polar front, in part compensating the initial increase in northward Ekman transport. Using an eddy-permitting oceanic model forced by the atmospheric variability of the last decades, Biastoch et al. (2009) showed that the observed poleward shift of the westerlies in the past two to three decades was associated with an increase of the Agulhas leakage. Consequently, more salty Indian Ocean waters have entered the Atlantic basin and begun to invade the North Atlantic, which may influence the future evolution of the AMOC. On the other hand, Treguier et al. (2010) found with an eddy-permitting oceanic hindcast that the MOC in the Southern Hemisphere was well correlated with the SAM at interannual and decadal time scales, while the eddy contribution to the MOC was chaotic in nature and uncorrelated with the SAM, so the model behavior was similar to that of coarseresolution models. Hence, although eddy-resolving climate models will ultimately be needed to capture realistically the effect of the SAM on the Southern Ocean and the AMOC, the role of oceanic eddies is still debated and it remains of interest to understand the behavior of the present generation of climate models, in particular those that parameterize the eddy effects.

The aim of this study is to investigate the main features of the natural variability of the austral region and the links between the Southern Hemisphere winds, the ACC, and the AMOC on different time scales. As the observations are too sparse and eddy-resolving climate models are not yet available, we use a control simulation of the IPSL CM4 climate model. The model was used with a rather coarse atmospheric resolution (LoRes version, to follow Marti et al. 2010) for the Intergovernmental Panel on Climate Change (IPCC) Fourth Assessment Report (AR4). As its representation of the Southern Ocean circulation was poor (Russell et al. 2006), we use a higherresolution version (HiRes; Marti et al. 2010) that compares better with the observations, as described in section 2 . Section 3 discusses the relations between the ACC, the SAM, and the global MOC in the Southern Hemisphere at the interannual time scale. In section 4 , we focus on the AMOC and discuss a SAM impact at the decadal time scales, while the link between the SAM and the AMOC at longer time scales is discussed in section 5 and conclusions are given in section 6 .

\section{Model description}

A control simulation with version HiRes of the IPSL CM4 model is used for this study. The atmospheric component of the model is Laboratoire de Météorologie 
Dynamique Zoomé (LMDZ; (Hourdin et al. 2006) with 144 longitudinal and 97 latitudinal grid points. As described by Marti et al. (2010), this is higher than the version LoRes $(96 \times 72)$ that was used for the IPCC AR4 and phase 3 of the Coupled Model Intercomparison Project (CMIP3) and rates poorly in its ability to simulate the Southern Ocean (Russell et al. 2006). This ability is largely improved in the present version of the model. There are 19 vertical levels in the atmosphere with hybrid $\sigma-p$ coordinates. Other components are identical to the LoRes version. The oceanic model is Océan Parallélisé 8 (OPA8; Madec et al. 1998) with a horizontal resolution based on a $2^{\circ}$ mesh and 31 vertical levels, with 10 levels in the top $100 \mathrm{~m}$. Mesoscale eddies that are crucial for representing the ACC (e.g., Marshall and Radko 2006; Treguier et al. 2007) are taken into account by a Gent and McWilliams parameterization, which similarly flattens the isopycnals using a coefficient that depends on the growth rate of baroclinic instabilities (usually varying from 15 to $3000 \mathrm{~m}^{2} \mathrm{~s}^{-1}$ ). Iudicone et al. (2008) argued that this parameterization led to a realistic representation of the ACC dynamics in the ocean component of the model. The land surface model is the Organizing Carbon and Hydrology in Dynamic Ecosystems (ORCHIDEE) model (Krinner et al. 2005) and the dynamic and thermodynamic sea ice model is the Louvain-la-Neuve Sea Ice Model (LIM; Fichefet and Morales-Maqueda 1999). The Ocean Atmosphere Sea Ice Soil (OASIS; Valcke 2006) coupler is used to synchronize the different components of the coupled model. The last 500 years of a 650-yr control run using constant 1860-level greenhouse forcing are to a reasonable approximation in a statistically stationary state and are used in this study.

The key features of the Southern Hemisphere climatology are well reproduced. As shown in Fig. 1, the mean surface wind stress is rather realistic but shifted toward the equator by about $5^{\circ}$ compared to the 40 -yr European Centre for Medium-Range Weather Forecasts (ECMWF) Re-Analysis (ERA-40). It is a general caveat of the IPSL model to represent the major atmospheric structures shifted equatorward (Marti et al. 2010). The ACC follows the line of maximum wind stress and it thus goes too far north after the Drake Passage. The mean transport across the Drake Passage is $90 \mathrm{~Sv}$. It is weaker than the observed transport (125-135 Sv; see Whitworth 1983; Whitworth and Peterson 1985) but more realistic than the $34 \mathrm{~Sv}$ of the LoRes version, where the maximum westerlies were located even further equatorward. The ACC and the wind stress are also too weak in the South Pacific. The zonal SST distribution in the Southern Ocean is quite realistic, except that the meridional temperature gradient is too weak near the ACC. However, there are two major biases in the model salinity (not shown). The surface waters are

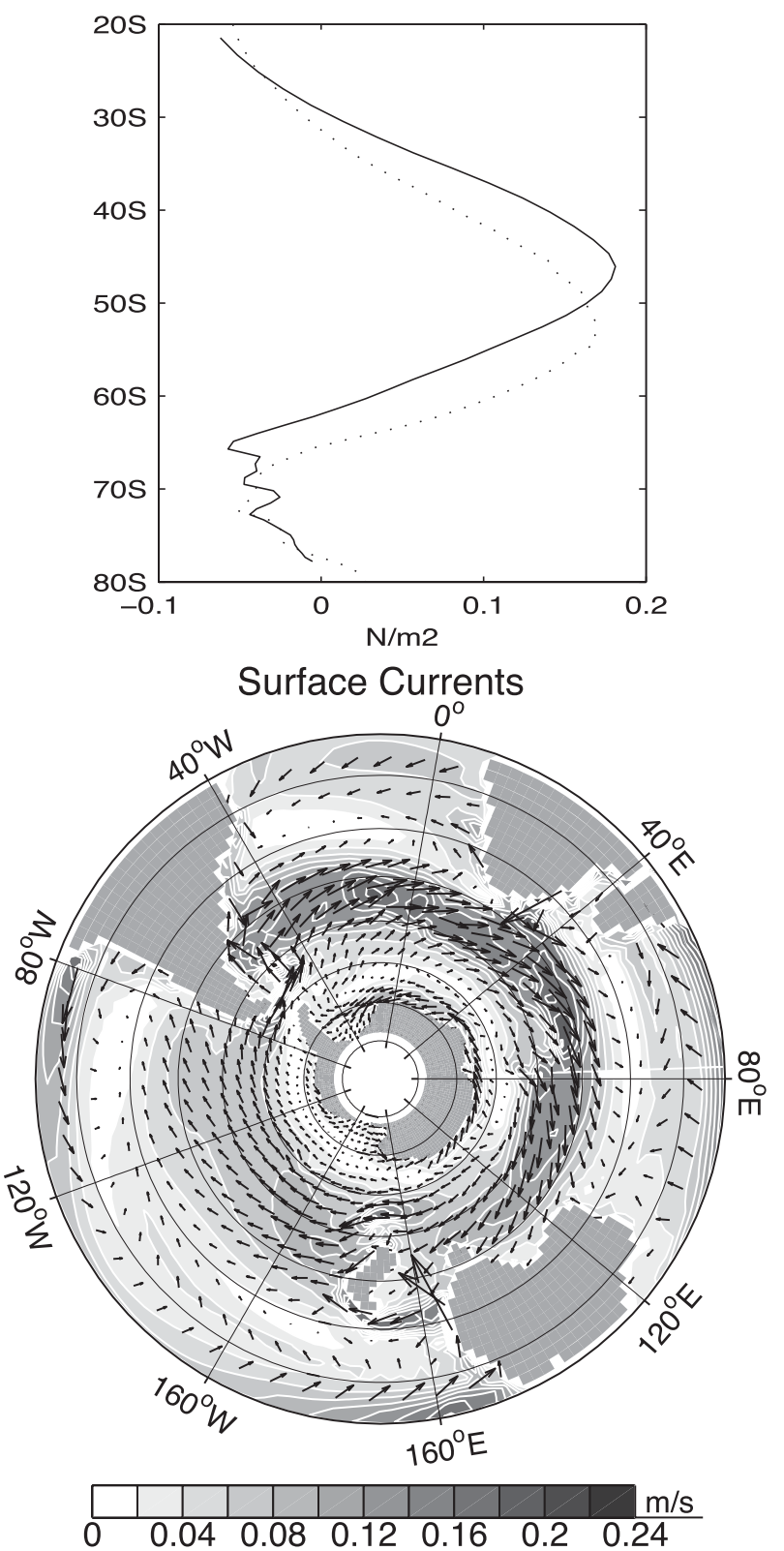

FIG. 1. (top) Climatology of zonally averaged zonal wind stress in the HiRes simulation (solid line) and in the ERA-40 reanalysis (dashed lines). (bottom) Climatology of surface currents and wind stress in the HiRes simulation. The grayscale indicates the norm of the vectors and the arrows their direction.

too fresh in the Pacific sector compared to the Levitus climatology (presumably because of too much sea ice melting during austral summer) and too salty south of Africa [primarily because the evaporation minus precipitation flux is too strong (not shown, but see Marti et al. 2010)]. The mean global MOC (including the parameterized eddy contribution) between $60^{\circ}$ and $30^{\circ} \mathrm{S}$ is shown in Fig. 2. There is a surface-intensified clockwise cell that results from the strong westerlies near $50^{\circ} \mathrm{S}$, 


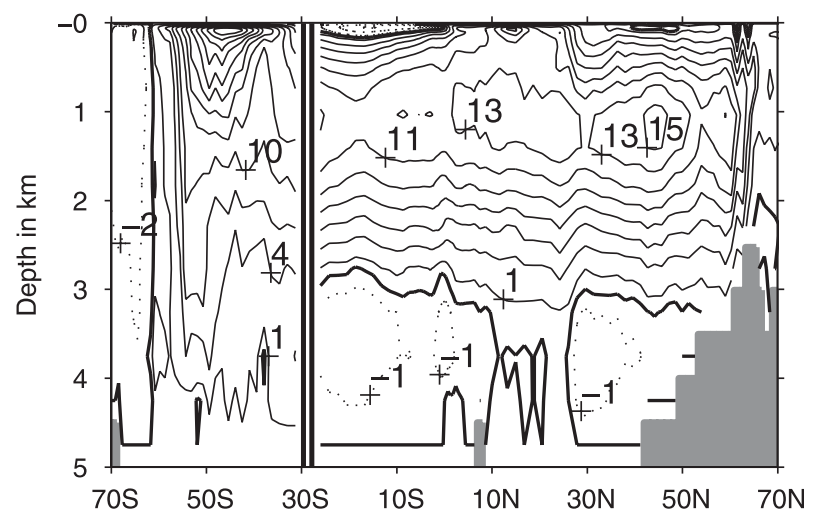

FIG. 2. Climatology of the global MOC south of $30^{\circ} \mathrm{S}$ and of the AMOC north of $30^{\circ} \mathrm{S}$ from the HiRes simulation. Contour interval is $3 \mathrm{~Sv}$ for the MOC and $2 \mathrm{~Sv}$ for the AMOC; dashed lines correspond to negative values and the thick line to zero.

which cause upwelling to the south and sinking to the north. Note that this cell would be stronger if the eddies were not taken into account, since they compensate a part of the Ekman transport along the ACC, albeit less than in models that explicitly represent them (Marshall and Radko 2006; Treguier et al. 2007). North of $30^{\circ} \mathrm{S}$, Fig. 2 only shows the Atlantic MOC, which is the major contributor to the global MOC. It has a maximum of $15 \mathrm{~Sv}$ near $45^{\circ} \mathrm{N}$ at a depth of $1100 \mathrm{~m}$, which is consistent with the observational estimate of $15 \mathrm{~Sv}$ by Ganachaud and Wunsch (2000).

The amount of incoming North Atlantic Deep Water (NADW) at $32^{\circ} \mathrm{S}$ plays an important role in the dynamics of the Southern Ocean, as this salty water is subject to both upwelling and mixing with the Antarctic Circumpolar Deep Water that circulates around Antarctica (Russell et al. 2006). Following Talley (2003), the amount of incoming NADW at $32^{\circ} \mathrm{S}$ is quantified by considering that its density is between $27.4 \sigma_{0}$ and $45.86 \sigma_{4} \mathrm{~kg} \mathrm{~m}^{-3}$ ( $\sigma_{0}$ and $\sigma_{4}$ are the potential density at 0 and $4000 \mathrm{~m}$, respectively). It averages to $14 \mathrm{~Sv}$, which is slighty less than the $17 \mathrm{~Sv}$ found in the observations (Talley 2003). Because the corresponding southward salt transport is a little too weak, the salinity gradient is too small, contributing to the too-weak zonal transport by the ACC. To summarize, the HiRes version of the IPSL CM4 coupled model shows performances in the Southern Ocean near the average of the other 18 coupled models of the IPCC AR4 (Russell et al. 2006).

\section{Interannual variability of the Southern Hemisphere atmosphere and its links with the Southern Ocean}

In the Southern Hemisphere, the leading mode of atmospheric variability is the SAM. It is primarily associated with zonally symmetric fluctuations of the strength and position of the westerlies (Thompson and Wallace 2000), and it is well represented by the first empirical orthogonal function (EOF) of the annual fluctuations of the sea level pressure (SLP) south of $20^{\circ} \mathrm{S}$ (Fig. 4, top). In the model, this mode explains $63 \%$ of the total yearly variance and it compares well with the observed one, although it is too zonally symmetric. A positive phase of the SAM corresponds to an intensification of the westerlies south of $45^{\circ} \mathrm{S}$ and a weakening to the north, so that the maximum zonal wind stress is shifted south. The spectrum of the normalized EOF time series (SAM index) corresponds to a white noise at time scales shorter than $50 \mathrm{yr}$, but is blue at longer periods (Fig. 3, top). As in the observations (Thompson and Wallace 2000; Hall and Visbeck 2002), the SAM depends little on seasons, although it is slightly stronger during austral summer.

In a positive phase of the SAM, the wind stress generates a northward Ekman transport along the ACC and a southward Ekman transport around $30^{\circ} \mathrm{S}$. The Ekman pumping is thus positive south of about $50^{\circ} \mathrm{S}$ and north of $30^{\circ} \mathrm{S}$, and negative in between (Fig. 4, bottom). Along Antarctica, the SAM is associated with an anomalous divergence of the surface currents that increases the isopycnals' slope in the Southern Ocean, resulting in a larger meridional pressure gradient. Since the ACC can be considered to be in geostrophic equilibrium far below the surface (Olbers et al. 2004), this increases the zonal current speed. As an index of the ACC variability, we use the annual time series of transport across the Drake Passage (Fig. 3, middle left). In the model, the transport varies between 80 and $100 \mathrm{~Sv}$, showing much year-to-year variability and strong low-frequency fluctuations. The power spectrum is red at low frequency but is approximately white at time scales shorter than $20 \mathrm{yr}$ (Fig. 3, middle right). Note that, unless otherwise noted, all results of this paper are based on yearly averages.

The SAM index and the ACC are only correlated with no time lag $(r=0.44)$, significant at the $5 \%$ level [significance is estimated as in Bretherton et al. (1999), assuming that time series are autoregressive processes of order 1]. This correlation is slightly lower than in the observations ( $r=0.68$; Meredith et al. 2004), or in the coarserresolution climate model of Hall and Visbeck (2002) $(r=0.5)$ and the high-resolution oceanic hindcast of Hughes et al. (2003) $(r=0.7)$.

In the southern Atlantic basin, shallow salinity anomalies appear in phase with—and $1 \mathrm{yr}$ after — a positive SAM (Fig. 5). The positive anomalies are primarily coming from the Indian and the Pacific basins. South of Africa, they are largely due to salinity advection by anomalous westward geostrophic currents flowing from south of Madagascar into the Atlantic basin. In the Pacific, they are generated 

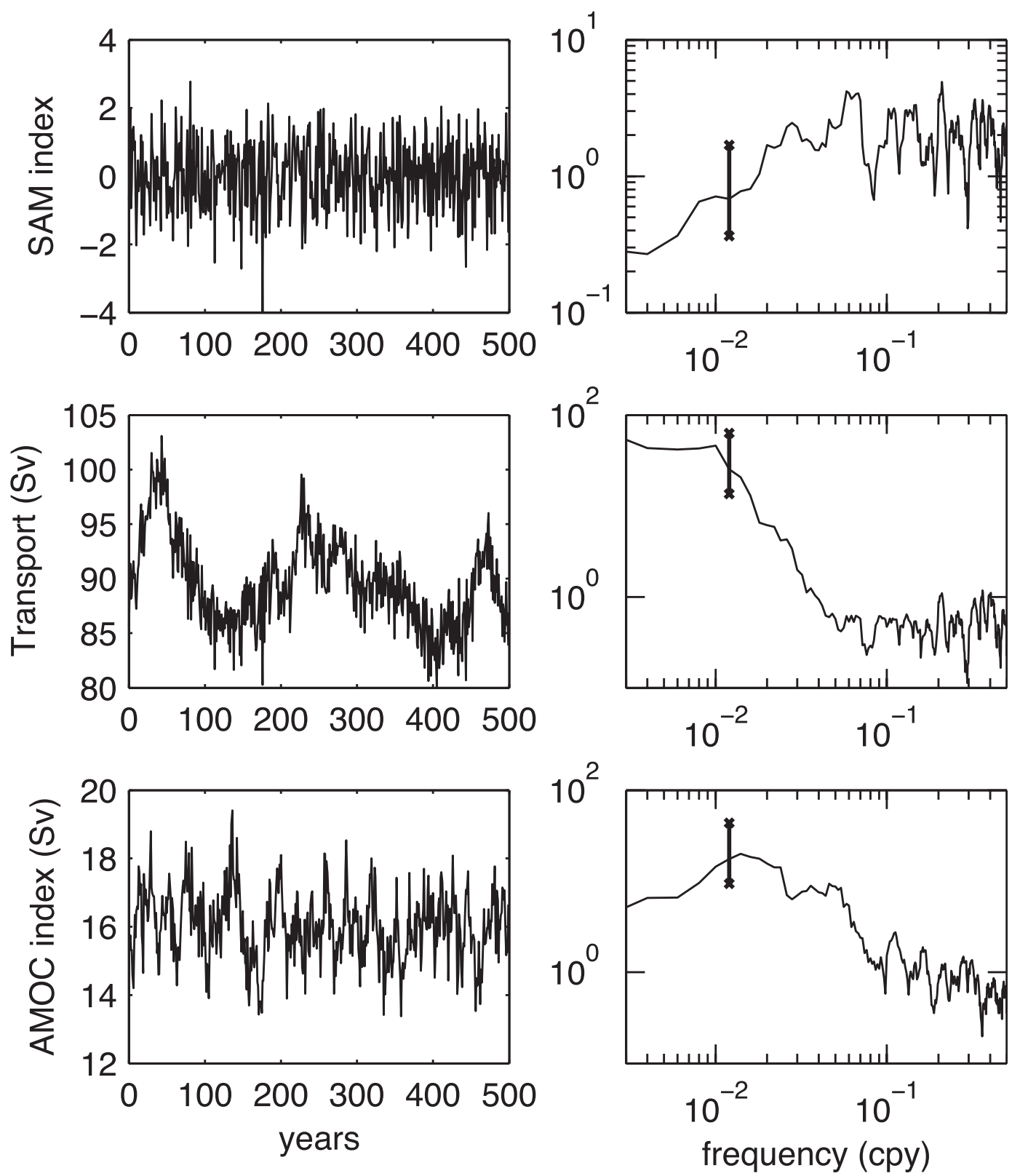

FIG. 3. (left) Time series and (right) power spectrum of, from top to bottom, the SAM index, the mass transport across the Drake Passage (in Sv), and the AMOC maximum below $500 \mathrm{~m}$ and between $30^{\circ}$ and $60^{\circ} \mathrm{N}$ (in Sv). Power spectra are estimated with the multitaper method (seven tapers). The $95 \%$ confidence interval is indicated.

by anomalous northward Ekman transport and then advected by the mean ACC into the Atlantic through the Drake Passage. These salinity anomalies circulate in the Atlantic basin but do not cross the equator before at least 8 yr. This is consistent with Speich et al. (2001), who found in a global ocean model that the shortest travel time for salinity anomalies from the Drake Passage and the southern tip of Africa to reach $20^{\circ} \mathrm{N}$ in the Atlantic was $11 \mathrm{yr}$, and the median travel time $50 \mathrm{yr}$. The impact of these anomalies onto the AMOC is discussed in section 5.
The strongest response of the Southern Ocean MOC to the SAM variability is fast and found at no lag in the regression in Fig. 6, which shows a nearly barotropic dipole reflecting the downwelling north of $50^{\circ} \mathrm{S}$ and the upwelling farther south expected from SAM Ekman pumping. The response pattern is very similar to the first EOF of the global MOC (not shown), which explains $43 \%$ of the yearly variance. This is consistent with Treguier et al. (2010), who showed that the MOC and the meridional Ekman transport in the Southern Hemisphere were 

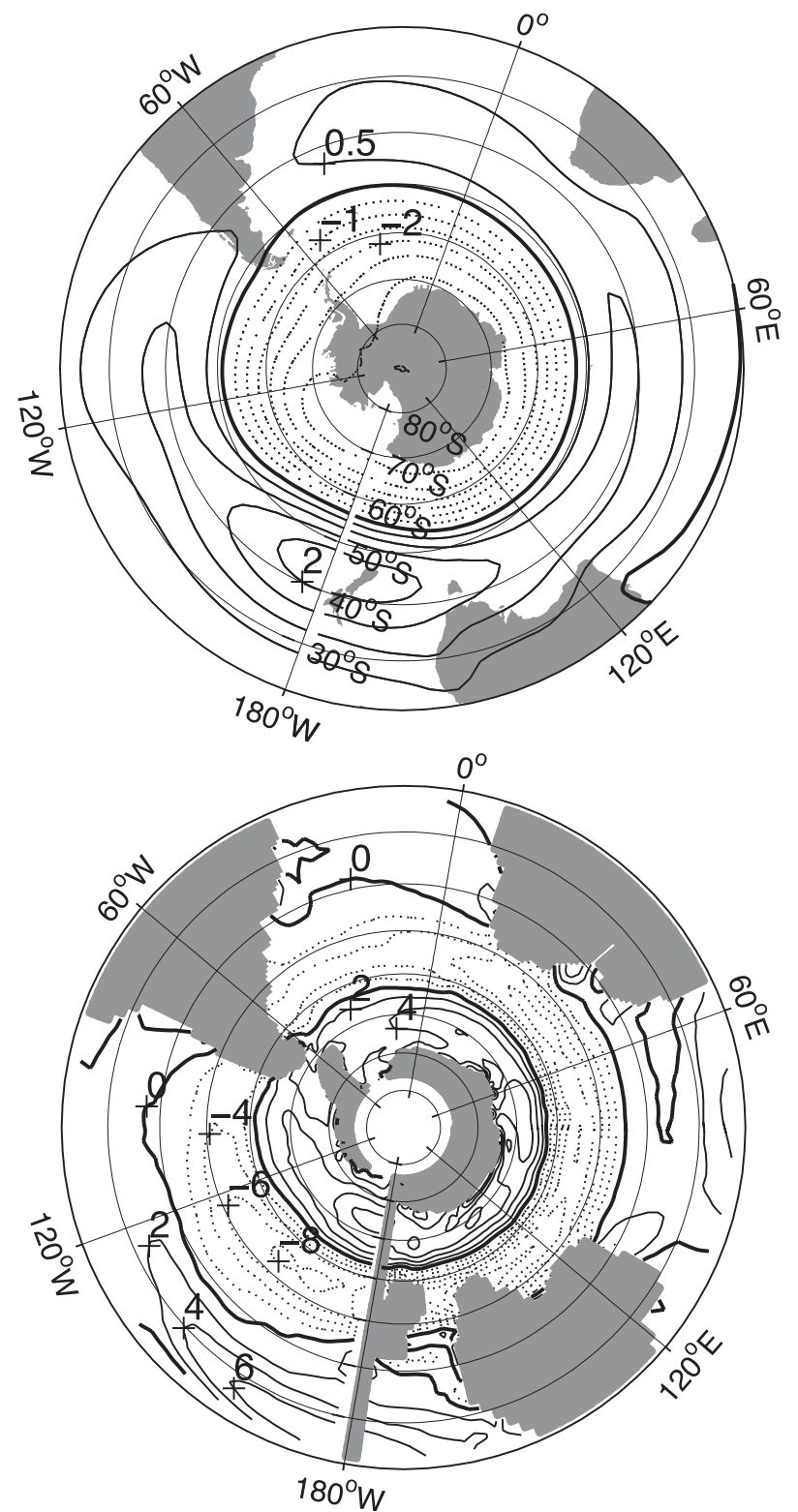

FIG. 4. (top) The SAM pattern, represented by the first EOF of the yearly SLP anomalies south of $20^{\circ} \mathrm{S}$. The EOF time series (SAM index) is normalized, and the contour interval is $0.5 \mathrm{hPa}$. (bottom) Regression of annual anomalies of Ekman pumping on the SAM index. Contour interval is $2 \mathrm{~m} \mathrm{yr}^{-1}$. Dashed lines correspond to negative values and the thick lines to zero.

highly correlated with the SAM index at interannual time scales, using an eddy-permitting oceanic model forced by an atmospheric reanalysis. Near the surface, the eddy contribution to the total MOC tends to counteract the Ekman transport and pumping (Fig. 6, top right), but its amplitude is an order of magnitude smaller. However, the eddy contribution peaks $2 \mathrm{yr}$ after a positive SAM, when it affects the whole water column and-although its amplitude is still low $(0.2 \mathrm{~Sv})$-nearly cancels the MOC response

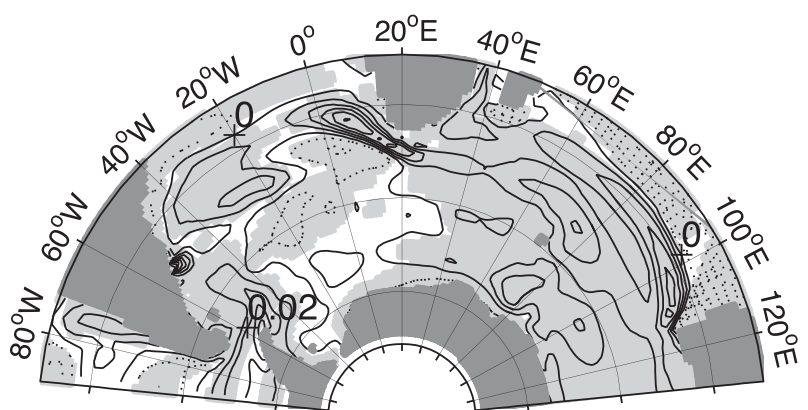

FIG. 5. Regression of annual anomalies of the averaged salinity between 0 and $100 \mathrm{~m}$ onto the SAM index when the SAM leads by $1 \mathrm{yr}$. Contour interval is $0.01 \mathrm{psu}$; dashed lines correspond to negative values. The shaded areas indicate that the regression is $5 \%$ significant.

near the ACC (Fig. 6, bottom). Interestingly, such a time lag in the parameterized eddy response to the SAM is broadly consistent with studies based on eddy-resolving models (e.g., Meredith and Hogg 2006; Screen et al. 2009), where the eddy activity lags a positive SAM by $2-3 \mathrm{yr}$, suggesting that the slow amplification of eddy activity may be linked to mean flow changes. At lower frequencies, the eddy contribution still plays a compensating role near the ACC, which may explain the lack of correlation of the ACC with the SAM discussed in section 5.

North of $30^{\circ} \mathrm{S}$, the MOC response to the SAM can be considered separately in each oceanic basin. The fast responses are very similar and concentrated in the Southern Hemisphere, with their contribution to the global MOC at $30^{\circ} \mathrm{S}$ partly reflecting their different width $(55 \%$ from the Pacific MOC, $35 \%$ for the Indian MOC, and $10 \%$ for the AMOC). In the following, we focus on the Atlantic basin.

\section{Relation between the AMOC and the SAM}

The main mode of atmospheric variability in the Northern Hemisphere-the North Atlantic Oscillation (NAO) - is thought to have a strong influence on the AMOC variability (e.g., Delworth et al. 1993; Eden and Willebrand 2001; Dong and Sutton 2005; Deshayes and Frankignoul 2008), primarily through a rapid adjustment to the wind stress and a slow response to anomalous heat fluxes and wind stress via convection in the northern North Atlantic. In the LoRes version of the IPSL CM4 model, it is primarily the east Atlantic pattern (EAP, which is the second mode of atmospheric variability in the North Atlantic) that forces the delayed AMOC intensification (Msadek and Frankignoul 2009). To single out the influence of the Southern Ocean westerlies on the AMOC, we have performed multiple linear regressions on the SAM, the EAP, and the NAO indices (the latter 

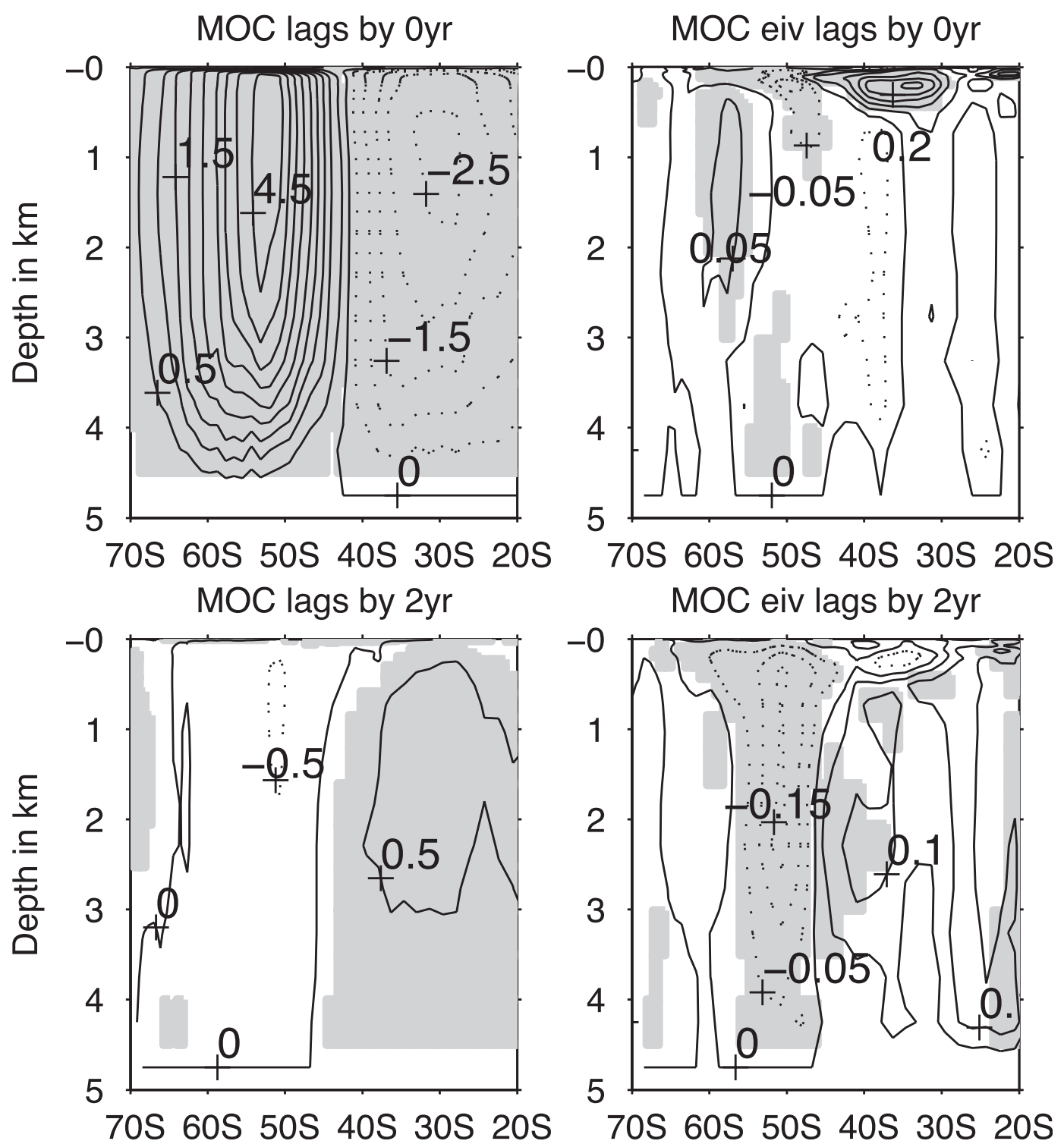

FIG. 6. (left) Regression of annual anomalies of the global MOC and (right) the eddy contribution to it on the SAM index at (top) zero lag and (bottom) $2 \mathrm{yr}$ after. Contour interval is (left) $0.5 \mathrm{~Sv}$ and (right) $0.05 \mathrm{~Sv}$. Dashed lines correspond to negative values. The shaded areas indicate that the regression is $5 \%$ significant.

two are computed as the first and second principal components of annual SLP anomalies in the area $20^{\circ}-80^{\circ} \mathrm{N}$, $90^{\circ} \mathrm{W}-40^{\circ} \mathrm{E}$ ), as described in appendix A. The SAM and NAO indices are indeed weakly correlated $(r=0.18$ for yearly values) both in the model and in the National Centers for Environmental Prediction (NCEP) reanalysis, although the correlation is only statistically significant in the former. On the other hand, the EAP is uncorrelated with the SAM and, of course, the NAO, so that the multiple linear regression is nearly equivalent to separate single regressions. As illustrated in Fig. 7 (left and middle), the in-phase AMOC response to the NAO and the
EAP forcing is equivalent barotropic, and is larger for the NAO, reflecting the stronger Ekman pumping. When the AMOC lags by $2 \mathrm{yr}$, anomalies change sign. The response to the NAO becomes very small by $3 \mathrm{yr}$ except at high latitudes, while the response to the EAP continues to evolve. The AMOC anomalies around $50^{\circ} \mathrm{N}$ keep growing and progressively expand into a basin-scale intensification of the AMOC, which peaks after $7 \mathrm{yr}$.

The AMOC patterns resulting from the multiple regressions are shown for the SAM index in Fig. 7 (right) at different lags. When the SAM leads by $1 \mathrm{yr}$, the AMOC anomalies in the Southern Hemisphere also change sign 

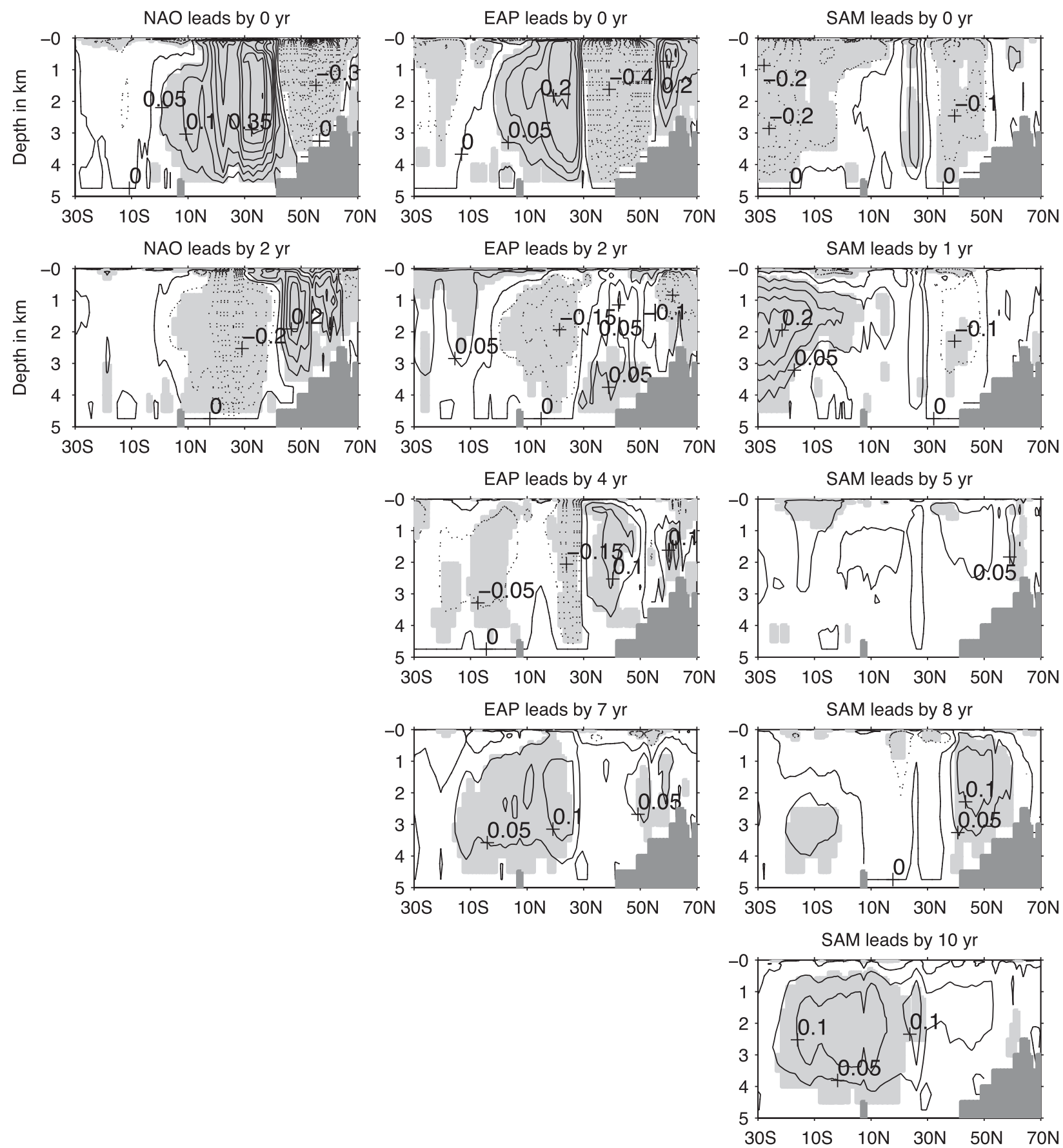

FIG. 7. Multiple linear regression of annual anomalies of the AMOC on the SAM, the NAO, and the EAP at different lags when the SAM leads. Contour interval is $0.05 \mathrm{~Sv}$; dashed lines correspond to negative values. The shaded areas indicate that the regression is $5 \%$ significant.

and become baroclinic, disappearing after $2 \mathrm{yr}$. There is thus a similarity in the direct response of the AMOC to the Southern and Northern Hemisphere atmospheric variability, but the dynamics of the sign reversal have not been elucidated. The lag 1 regression shows that at $30^{\circ} \mathrm{S}$ the flow below $2500 \mathrm{~m}$ is southward. This results in a small but significant correlation $(r=0.23)$ when the SAM leads the incoming NADW at $30^{\circ} \mathrm{S}$ by $1 \mathrm{yr}$.

Significant anomalies are also found in the North Atlantic at lag 0, but they decrease rapidly. However, a growing intensification of the AMOC appears in the northern North Atlantic, starting 4 yr after a positive 
SAM, but more clearly seen at lag 5 (Fig. 7, right). These remote responses to the SAM cannot be explained by the propagation of oceanic anomalies from the Southern to the Northern Hemisphere, since the time scale is too short. They are, rather, due to atmospheric teleconnections. As the results are unchanged if simple (instead of multiple) regressions are performed, the mechanism is thereafter investigated through simple regressions.

During a positive SAM, there is a significant anomalous SLP low in the northern North Atlantic (Fig. 8, top). The signal is stronger in boreal winter, and it is primarily linked to El Niño-Southern Oscillation (ENSO) teleconnections. Because of a symmetric ENSO forcing of the Northern and Southern Hemispheres, La Niña conditions are associated at no lag with a positive SAM and negative SLP anomalies in the northern North Atlantic. This is shown by the SLP regression mapped onto the ENSO-3.4 index (Fig. 8, middle), which is very similar to the SLP regression mapped onto the SAM index, except for a change of sign and larger anomalies. Consistent with Seager et al. (2003), the observations [NCEP reanalysis for SLP (Kalnay et al. 1996) and Hadley Centre Global Sea Ice and Sea Surface Temperature (HadISST) for SST (Rayner et al. 2003)] similarly show that a negative SAM, albeit much less zonally symmetric than in the model, is associated with El Niño (Fig. 8, bottom). Negative SLP anomalies in the North Atlantic are also seen in the observations, but they extend farther north than in the model, which is linked to a general bias of coupled models (Brönnimann 2007), and the high over Greenland is much weaker. In the model, the wind stress associated with these SLP anomalies in the northern North Atlantic induces local Ekman pumping that reaches $-1.5 \mathrm{~m} \mathrm{yr}^{-1}$ around $30^{\circ} \mathrm{N}$ and $1.5 \mathrm{~m} \mathrm{yr}^{-1}$ around $50^{\circ} \mathrm{N}$ (not shown). This generates the strong $\mathrm{AMOC}$ response between about $30^{\circ}$ and $50^{\circ} \mathrm{N}$ seen in the unlagged regression of the AMOC onto the SAM (Fig. 7, top right). The AMOC regression onto a "filtered" SAM index where the ENSO signal has been removed (as described in appendix B) shows at no lag a negligible signal north of $15^{\circ} \mathrm{N}$ (not shown), thereby confirming the role of ENSO in this teleconnection.

To explain the longer-term (lag 4 and later) response of the AMOC seen on Fig. 7 (right), one must take into account the fact that the ENSO influence is not the only mechanism that links the SAM to the North Atlantic signal. Indeed, a regression of the North Atlantic atmospheric fields onto the "ENSO-filtered" SAM index shows significant (albeit smaller) SLP anomalies centered on the west coast of Greenland (not shown) and, more importantly, substantial easterlies appearing 6-12 months after a positive SAM (1 $\mathrm{yr}$ after a positive SAM for annual anomalies; Fig. 9). Such a relatively long time lag suggests that the interhemispheric link involves the ocean.
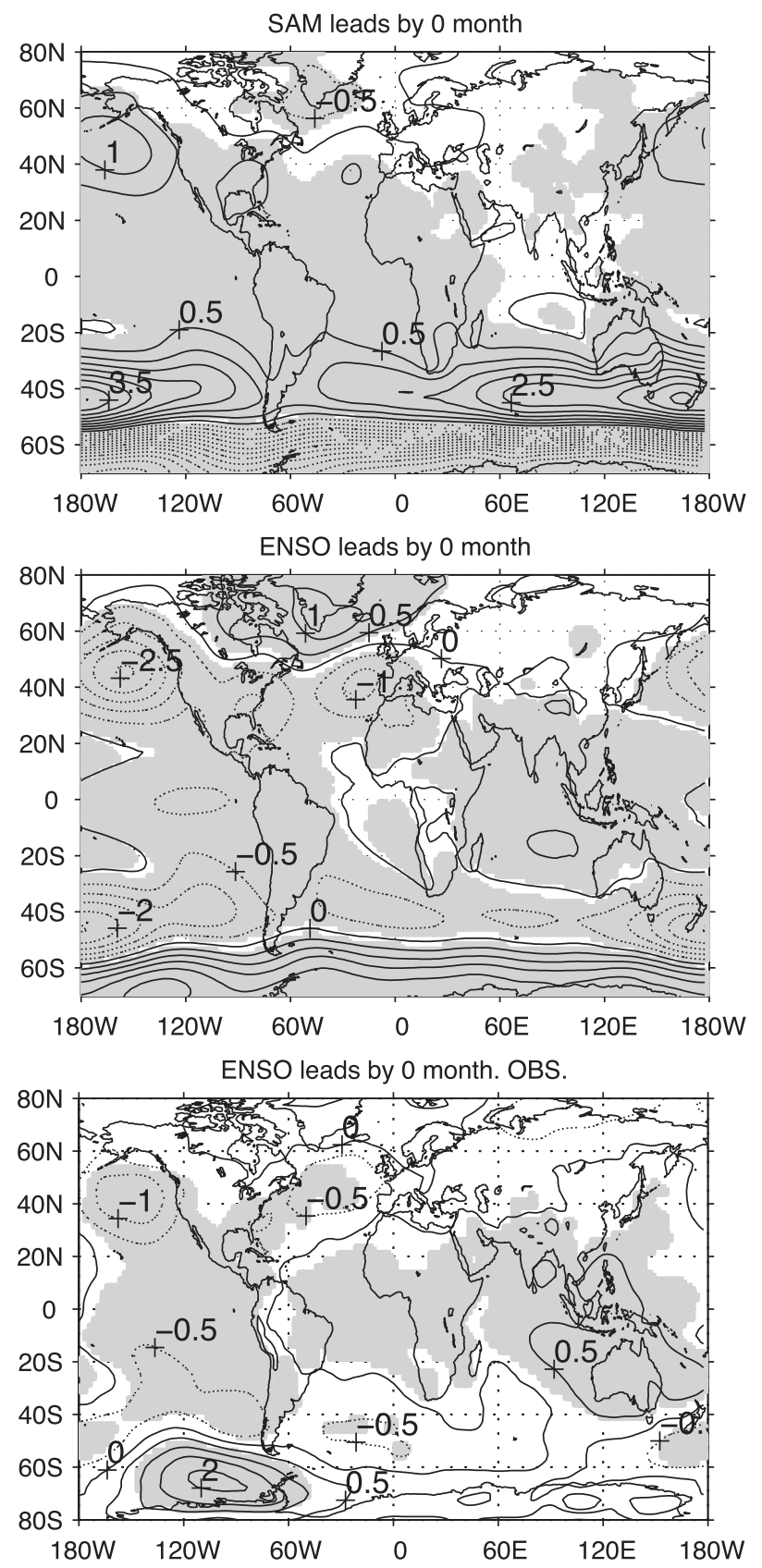

FIG. 8. Regression of monthly anomalies of the SLP mapped onto (top) the SAM index in the model, (middle) ENSO in the model, and (bottom) ENSO in the observations during 1993-2008. Contour interval is $0.5 \mathrm{hPa}$. Dashed lines correspond to negative values. The shaded areas indicate that the regression is $5 \%$ significant.

Thompson and Lorenz (2004) showed that the SAM has a significant signature in the tropics and the subtropics of both hemispheres during the cold season, after about 2 weeks. We speculate that this atmospheric teleconnection modifies the tropical and subtropical SST, which introduces an additional delay. The resulting SST anomalies should 

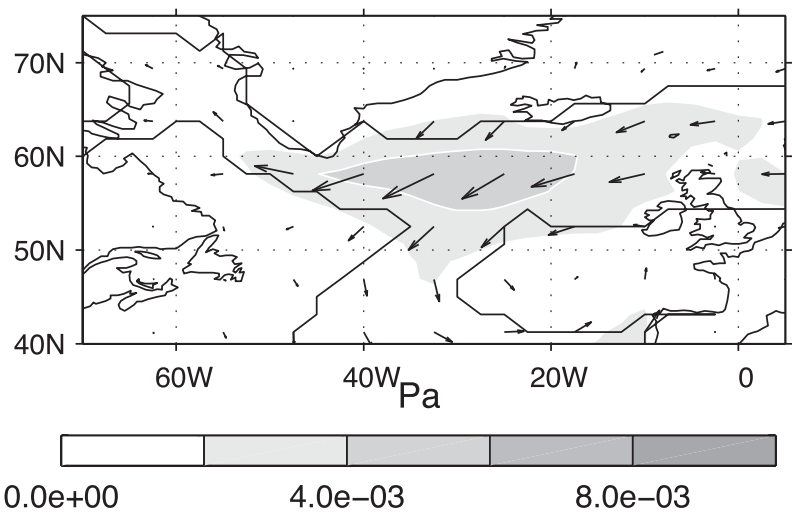

FIG. 9. Regression of annual anomalies of ENSO-filtered surface wind stress onto ENSO-filtered SAM index when it leads by $1 \mathrm{yr}$. Arrows indicate the direction and gray shadings the norm of wind stress anomalies. The solid line indicates the limit of $5 \%$ significant regression.

then affect the high northern latitudes via an atmospheric teleconnection, introducing a further 1- or 2-month delay (Liu and Alexander 2007). Whether this scenario is plausible, however, remains to be established.

In any case, wind stress anomalies reflecting this interhemispheric teleconnection (Fig. 9) as well as ENSO forcing both drive anomalous currents, in particular in the Irminger Sea (Fig. 10, top). A positive salinity anomaly reaching up to 500-m depth then rapidly appears between the tip of Greenland and Iceland, primarily resulting from anomalous salinity advection and mean salinity advection along the East Greenland Current and the North Atlantic Current (Fig. 10, middle). Evaporation and precipitation play a lesser role, since their regression onto the SAM is not significant. It can be shown that the salinity anomalies associated with the ENSO index are not very persistent, changing sign $2 \mathrm{yr}$ later, probably because of the 3-yr period of ENSO in the model. By contrast, salinity anomalies associated with the ENSO-filtered SAM index are quite persistent, remaining significant in the regression up to $7 \mathrm{yr}$ after the SAM. Note that because of the integrating aspect of the oceanic response, such regressions cannot truly separate the contribution of the two forcings, yet the close similarity (not shown) between the regressions on the ENSO-filtered and that on the raw SAM indices suggests that the direct ENSO forcing plays a lesser role at larger lags. The associated density anomalies, which have a similar regression pattern on the SAM index (not shown), lead to a deepening of the winter mixed layer in the model deep convection area between the tip of Greenland and Iceland (thick contour in Fig. 10), peaking $4 \mathrm{yr}$ after a positive SAM (Fig. 10, bottom). As a result, significant clockwise AMOC anomalies appear near $50^{\circ} \mathrm{N}$ about $4 \mathrm{yr}$ after a positive SAM, and they grow-slowly expanding and moving southward with increasing lags. By lag 8 , the
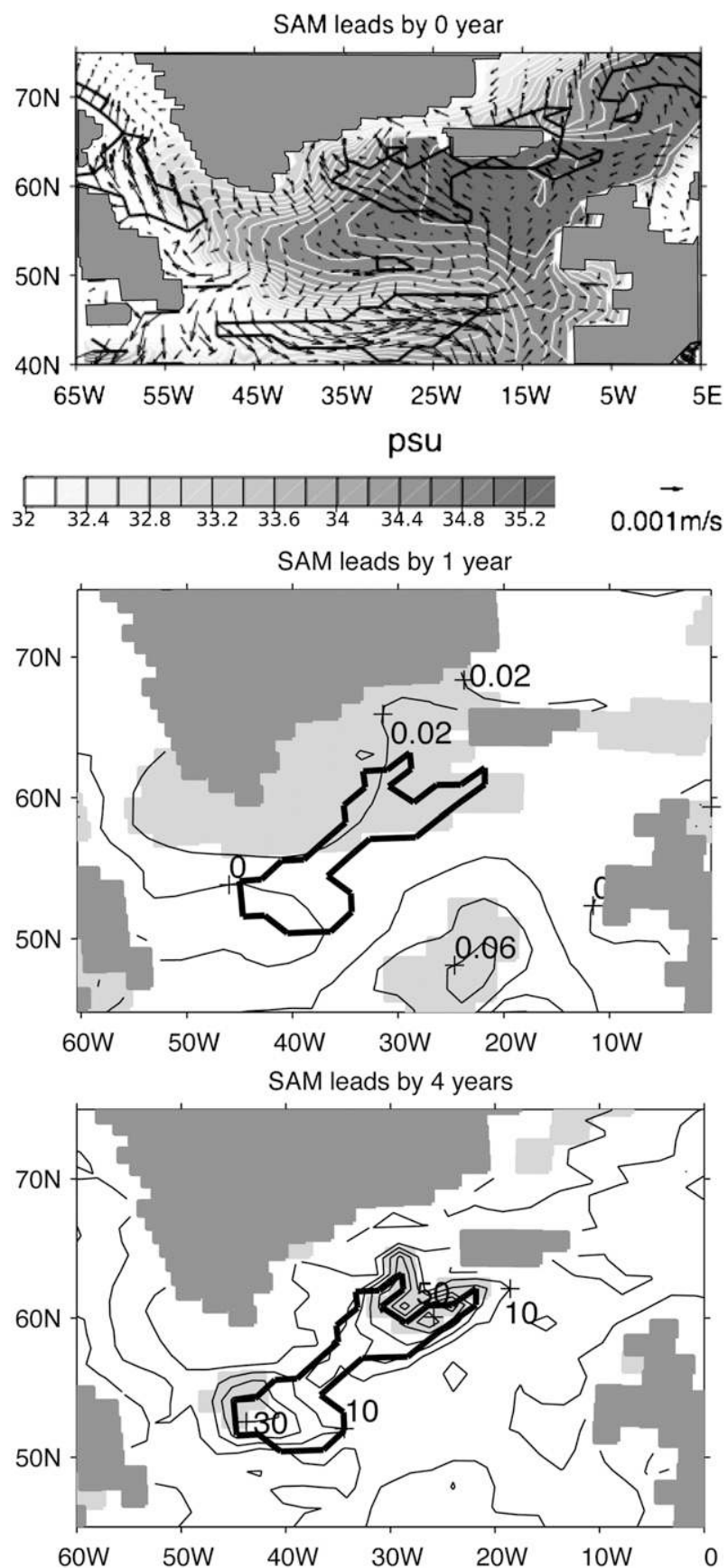

FIG. 10. (top) Linear regression onto the SAM index of surface currents superposed on the mean surface salinity field with no time lag. Thick lines indicate the limit of significant areas. (middle) Surface salinity $1 \mathrm{yr}$ later (contour interval $0.02 \mathrm{psu}$ ). The shaded areas indicate that the regression is $5 \%$ significant. (bottom) Winter mixed-layer depth 4 yr later (contour interval $10 \mathrm{~m}$ ). The shaded areas indicate that the regression is $5 \%$ significant. The thick contour in bottom two panels indicates the mean convective area of the model. 

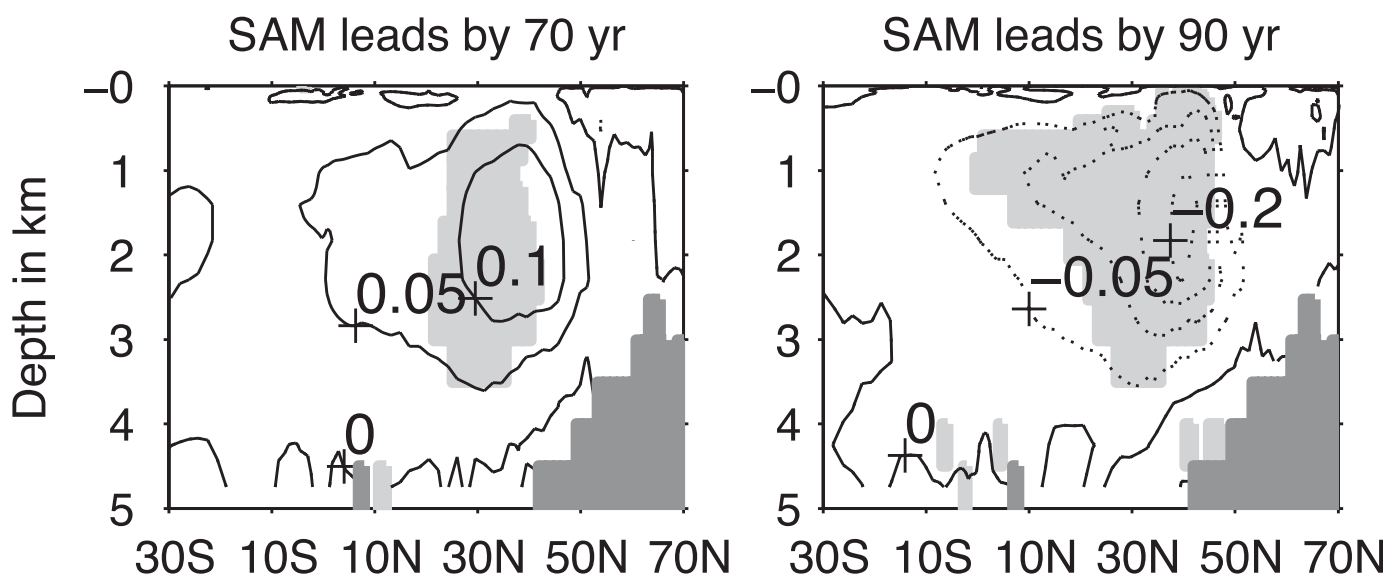

FIG. 11. Regression of anomalies of low-pass-filtered $\left(T_{c}=10 \mathrm{yr}\right)$ AMOC on the SAM index, when the latter leads by 70 and $90 \mathrm{yr}$. Contour interval is $0.05 \mathrm{~Sv}$; dashed lines correspond to negative values. The shaded areas indicate that the regression is $10 \%$ significant.

clockwise circulation cell has expanded but remains centered at $50^{\circ} \mathrm{N}$, whereas it is shifted south and reaches $30^{\circ} \mathrm{S}$ by lag 10 (Fig. 7, right) before slowly disappearing. The signal is weak $(\sim 0.15 \mathrm{~Sv})$ yet it corresponds to $15 \%$ of the maximum standard deviation of the AMOC variability, and it is similar to the AMOC response to the EAP (Fig. 7, middle). Its statistical significance was confirmed by a Monte Carlo test, where the regression was repeated 500 times, linking the original AMOC anomalies with randomly permuted SAM based on blocks of 2 and 4 successive years.

\section{Links between the southern circulation and the AMOC at multidecadal scale}

Since the salinity anomalies generated in the Southern Ocean by the SAM variability (see Fig. 5) only slowly propagate northward in the Atlantic, as discussed in section 3, their impact on the AMOC is best investigated by considering low-pass-filtered data. We first use a lowpass Butterworth filter with a cutoff period of $T_{c}=10 \mathrm{yr}$. As shown by the regression in Fig. 11 (left), the AMOC is accelerated about $70 \mathrm{yr}$ after a positive SAM phase. The signal is weak, $\sim 0.1 \mathrm{~Sv}$ for a typical SAM fluctuation, yet it corresponds to about $12.5 \%$ of the maximum standard deviation of the low-pass AMOC variability. Statistical significance was estimated by a Student's $t$ test with $T /\left(T_{c} / 2\right)$ degrees of freedom ( $T$ being the length of the time series), consistent with the effective Nyquist frequency, and its robustness was confirmed by a Monte Carlo method, where the regression was repeated 500 times, linking the filtered AMOC anomalies with randomly permuted SAM based on blocks of 25 and 50 successive years. In the figures, we use for clarity the $10 \%$ significance level, as the number of number of freedom is smaller, but the main features are $5 \%$ significant, albeit in a smaller area.
The delayed intensification of the AMOC appears to be due to the interhemispheric propagation of the salinity anomalies driven by the SAM. Indeed, the positive salinity anomalies in Fig. 5 propagate northward in the Atlantic Ocean, cross the equator after a decade (not shown), and spread into the northern subtropical gyre about 10 yr later (Fig. 12). The signal becomes too noisy at longer time lag to be traced farther north, although it appears in the Hovmöller diagram in Fig. 13, where a slightly stronger low-pass filter $\left(T_{c}=20 \mathrm{yr}\right)$ has been used to more clearly show the salinity propagation up to the subtropical gyre. We suggest that the salinity anomalies

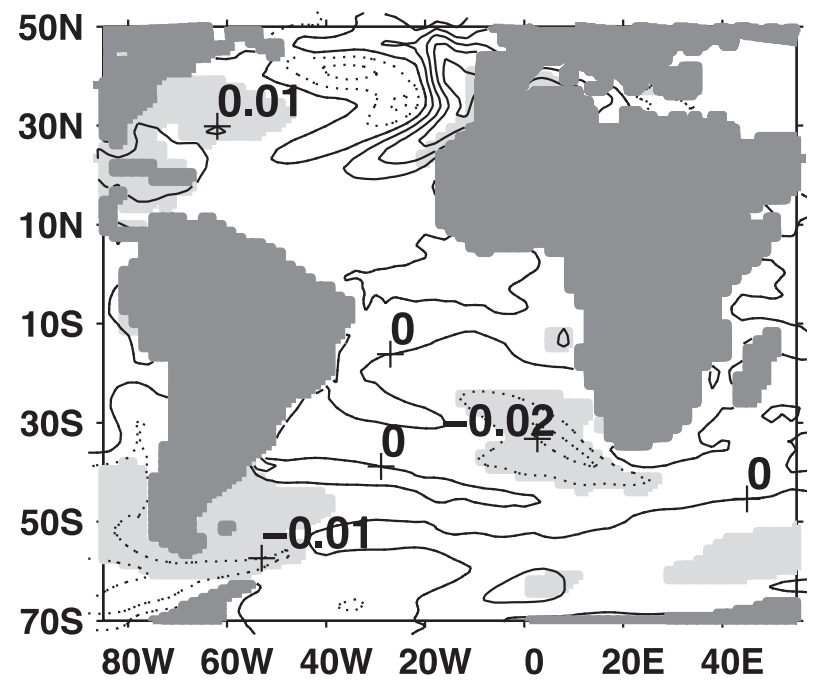

FIG. 12. Regression of low-pass-filtered $\left(T_{c}=10 \mathrm{yr}\right)$ salinity anomalies averaged between 0 and $100 \mathrm{~m}$ onto the SAM index, when the latter leads by $20 \mathrm{yr}$. Contour interval is $0.01 \mathrm{psu}$; dashed lines correspond to negative values. The shaded areas indicate that the regression is $10 \%$ significant. 


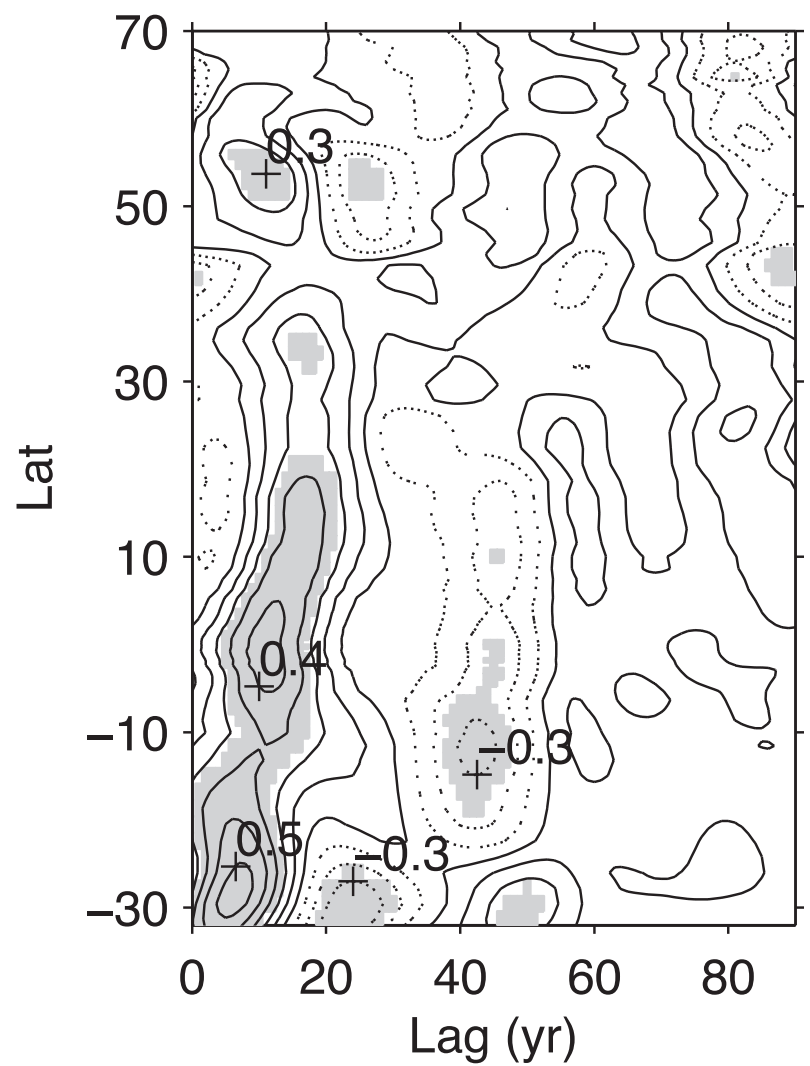

FIG. 13. Correlation between low-pass-filtered $\left(T_{c}=20 \mathrm{yr}\right)$ zonally averaged salinity in the Atlantic $(0-100 \mathrm{~m})$ and the SAM index. Contour interval is 0.1 ; dashed lines correspond to negative values. The shaded areas indicate that the regression is $10 \%$ significant.

circulate in the subtropical gyre and subduct in its center before being advected northward in the subsurface along the North Atlantic Current. Indeed, 65 yr after a positive SAM, positive anomalies are found southeast of Greenland between 200- and 300-m depth (isopycnals $26.4 \sigma_{0}-27.2 \sigma_{0}$; Fig. 14). The arrival of the more salty waters in the northern North Atlantic leads to an anomalous deepening of the mixed layer in the convective area south of Greenland about $70 \mathrm{yr}$ after a positive SAM (not shown), and it thus intensifies the AMOC.

To verify that the implied northward advection time is consistent with the model circulation, we launched about 25000 fictitious Lagrangian floats in the upper $100 \mathrm{~m}$ of the Drake Passage and near the tip of Africa (section at $16^{\circ} \mathrm{E}$ between $40^{\circ}$ and $50^{\circ} \mathrm{S}$ ) where positive salinity anomalies enter the Atlantic basin in a positive phase of the SAM (Fig. 5). The float trajectories are computed by the Ariane tool (Blanke and Raynaud 1997) using the model climatological monthly tridimensional currents. Among particles launched in the Drake Passage, 21\% reach the $40^{\circ} \mathrm{N}$ section: $19 \%$ below the $100-\mathrm{m}$ depth with

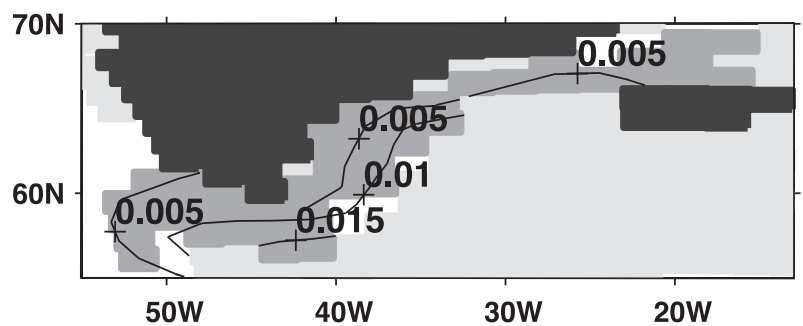

FIG. 14. Regression of low-pass-filtered $\left(T_{c}=10 \mathrm{yr}\right)$ salinity anomalies on the isopycnal surface $27 \sigma_{0}$ onto the SAM index, when the latter leads by $65 \mathrm{yr}$. Contour interval is $0.005 \mathrm{psu}$. The gray shaded areas indicate that the regression is $10 \%$ significant. The light shading indicates grid points where the regression is not computed, as the density of $27 \sigma_{0}$ is reached less than $60 \%$ of the year.

a median travel time $\left(T_{m}\right)$ of $120 \mathrm{yr}$ and $2 \%$ in the upper $100 \mathrm{~m}$ with $T_{m}=70 \mathrm{yr}$. Most of the remaining particles complete one revolution around Antarctica (74\%) with $T_{m}=30 \mathrm{yr}$. A much larger percentage of the particles launched near the tip of Africa reach the $40^{\circ} \mathrm{N}$ section: $55 \%$ below $100-\mathrm{m}$ depth with $T_{m}=44 \mathrm{yr}$ and $6 \%$ in the upper $100 \mathrm{~m}$ with $T_{m}=21 \mathrm{yr}$. Hence, as shown by Friocourt et al. (2005), the bulk of the water reaching the North Atlantic comes from the Indian Ocean by the Agulhas Current. A few float trajectories that reach the North Atlantic are shown in Fig. 15 (top). Although there is much dispersion, they generally reach the North Hemisphere subtropical gyre in $20-40$ yr. After subduction and recirculation in the gyre, they travel north toward the tip of Greenland. They reach the convective area of the subpolar gyre with a median travel time of $65 \mathrm{yr}$, sink, and then travel back southward in the deep ocean. We also launched fictitious drifters in the northwestern tropics, where the salinity signal was seen about $20 \mathrm{yr}$ after a positive SAM. Three trajectories are illustrated in Fig. 15 (bottom), where the color coding indicates their depth. The drifters reach the northern North Atlantic after 30-50 yr and sink. These traveling times are thus broadly consistent with the lagged correlation between the SAM and the AMOC, and they are also comparable to the travel time found by Mignot and Frankignoul $(2005,2009)$.

The regression in Fig. 11 (right) shows that the AMOC intensification at lag 70 is followed by a slowdown $20 \mathrm{yr}$ later. This seems to be due to the same advective process as above but for salinity anomalies of opposite sign. Indeed, negative salinity anomalies enter in the South Atlantic from both the Indian and the Pacific basins about $20 \mathrm{yr}$ after a positive SAM and thus $20 \mathrm{yr}$ after the positive salinity anomalies that eventually lead to the AMOC acceleration discussed above (Figs. 12 and 13). In the Indian basin, the freshening is primarily generated by 


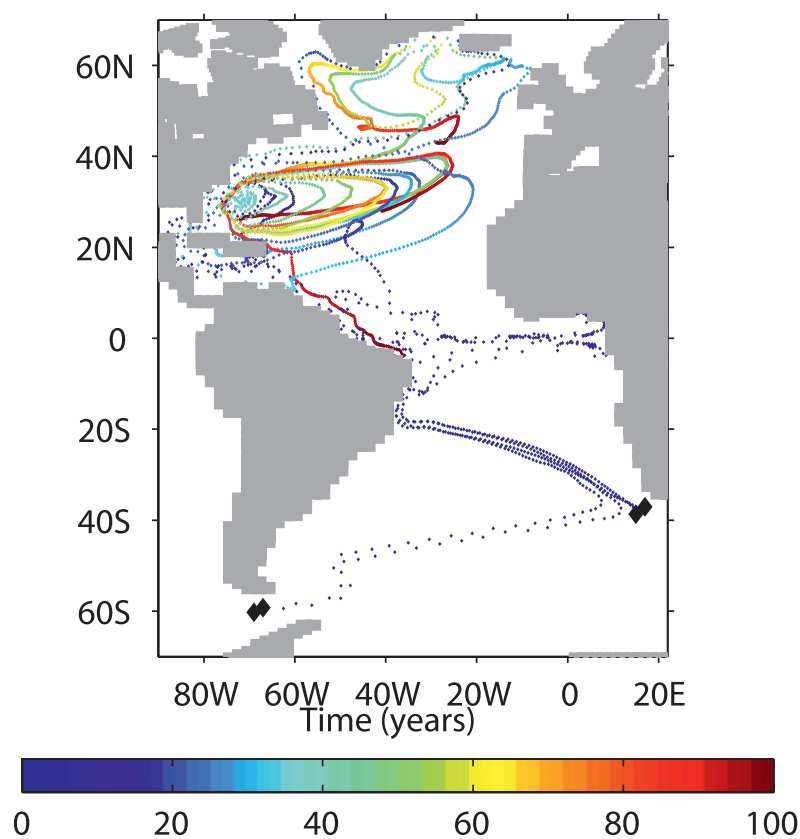

0
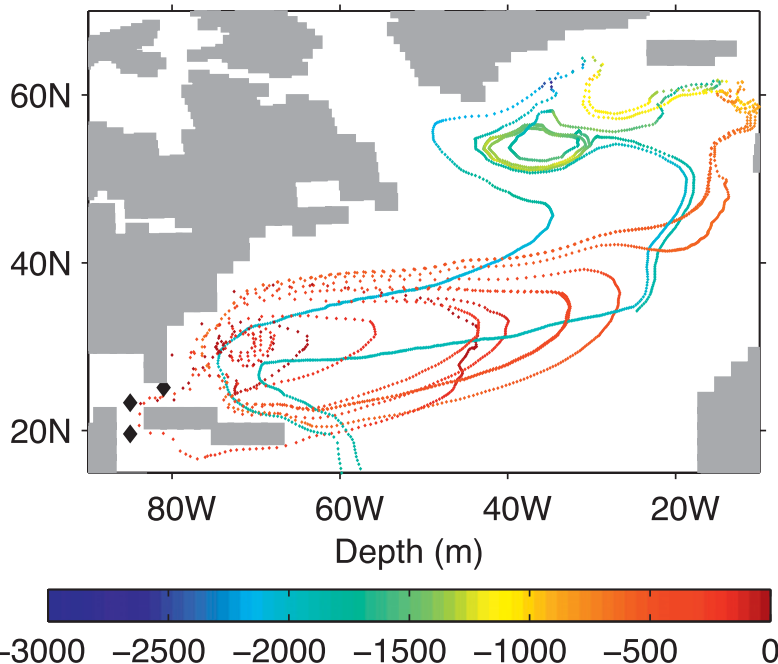

FIG. 15. Lagrangian trajectories of the fictitious drifters advected by mean currents for 100 yr. (top) Drifters launched (black diamonds) in the Drake Passage and near the tip of Africa; they reach the northern North Atlantic after about $40 \mathrm{yr}$. The colors indicate the travel time of the drifters. (bottom) Drifters launched in the tropics; they reach the northern North Atlantic after about $30 \mathrm{yr}$. The colors indicate the depth of the drifters.

anomalous southward advection of the mean salinity field due to SAM-driven currents near the west coast of Australia (Fig. 5). The negative salinity anomalies are then advected by the mean currents toward Madagascar and then into the Atlantic basin by the Agulhas Current. In the Pacific basin, strong negative salinity anomalies appear about $10 \mathrm{yr}$ after a positive SAM near Antarctica between $150^{\circ} \mathrm{E}$ and $180^{\circ}$ (not shown). They are linked to

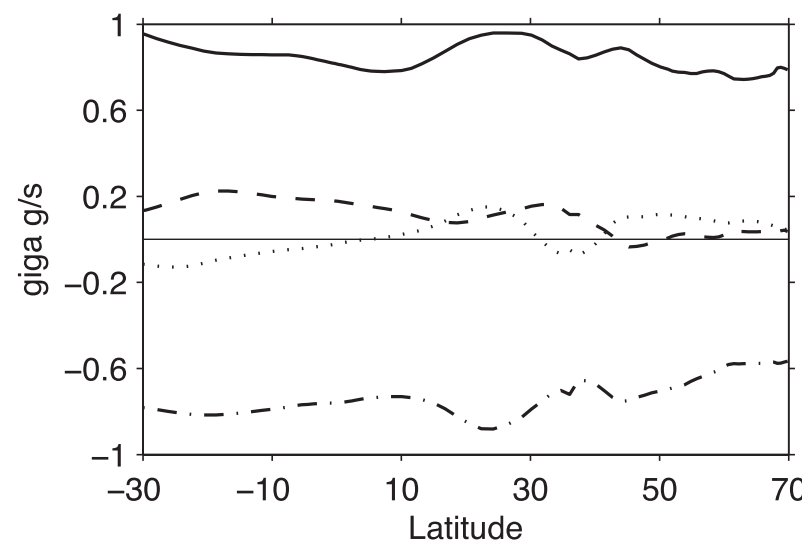

FIG. 16. Regression of low-pass-filtered $\left(T_{c}=10 \mathrm{yr}\right)$ meridional salt transport (in $\mathrm{Gg} \mathrm{s}^{-1}$ ) onto the low-pass-filtered SAM index when the SAM leads by $5 \mathrm{yr}$ (solid line), by $15 \mathrm{yr}$ (dashed), by $25 \mathrm{yr}$ (dashed-dotted), and by $35 \mathrm{yr}$ (dotted). Note that it is computed from $150 \mathrm{yr}$ of data.

salinity advection by anomalous eastward currents that are particularly strong at lag 10 and to ice melting (not shown). These negative salinity anomalies are then advected by the ACC, entering in the Atlantic by the Drake Passage. Hence, $20 \mathrm{yr}$ after a positive SAM, the salinity anomalies entering the Atlantic basin are opposite to those in Fig. 5 and they should correspondingly reduce the AMOC $20 \mathrm{yr}$ after it has intensified, as seen in Fig. 12. The 20-yr reversal is also clearly seen in the regression of the meridional salt transport onto the SAM index (Fig. 16), which suggests an oscillatory behavior. Note that the meridional salt transport could only be estimated in a 150 -yr sequence in which the data had been saved, so this calculation has to be considered with caution.

Although the control simulation is too short (500 yr) to investigate the longer time scales with much confidence, the AMOC seems to be almost adjusted to the SAM changes in time scales longer than $100 \mathrm{yr}$, consistent with the simulation of Toggweiler and Samuels (1995), Sijp and England (2009), and others, supporting that stronger westerlies lead to a stronger AMOC. This is suggested by Fig. 17, which shows that the AMOC index (maximum of the AMOC below 500-m depth and between $30^{\circ}$ and $60^{\circ} \mathrm{N}$ ) and the SAM evolve approximately in phase when low-pass filtered with a cutoff period of $60 \mathrm{yr}$. This is also suggested by the significant coherency between the AMOC and the SAM at periods longer than about $100 \mathrm{yr}$, with the SAM leading the AMOC by a decade or two (not shown). Whether such a small lag results from a mixture of the processes discussed in sections 4 and 5 can only be speculated upon.

On the other hand, we found no link between the SAM (or the AMOC) and the ACC at the centennial time scale, suggesting that the large centennial variability of 


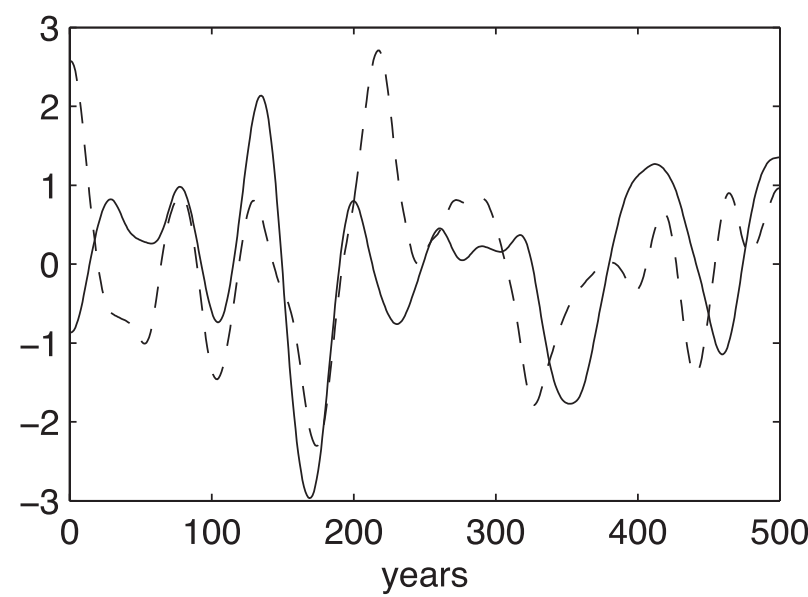

FIG. 17. Normalized time series of the SAM index (dashed line) and of AMOC index (solid line) filtered with a cutoff period of $60 \mathrm{yr}$.

the Drake Passage transport seen in Fig. 3 reflects slow changes in the hydrography of the Southern Ocean in the Indian and Pacific basins. These changes are, however, beyond the scope of a study that focuses on the influence of the southern winds on the AMOC.

The lack of link between the SAM and the ACC is likely to result from the fact that, at this long time scale, the sloping of the isopycnals in the Southern Ocean associated with westerly enhancement is compensated by an increase in the eddies' activity that flattens the isopycnals' slope, as discussed in section 3.

\section{Summary and conclusions}

The links between the SAM, the ACC, and the AMOC have been investigated in a 500-yr control run of the HiRes version of the IPSL climate model. Although this version is more realistic than the LoRes version discussed by Russell et al. (2006), it has some limitations: the Southern Hemisphere westerlies are located too far north; the amount of incoming NADW at $30^{\circ} \mathrm{S}$ in the Atlantic is slightly underestimated; and the ACC, transporting about $90 \mathrm{~Sv}$, is too weak compared to the observations. Nonetheless, the main features of the Southern Ocean circulation are sufficiently well represented to investigate its variability on the annual-to-multidecadal time scales. Eddies are not resolved, but the Gent and McWilliams parameterization with a coefficient depending on the growth rate of baroclinic instabilities seems to represent them acceptably, as suggested by Iudicone et al. (2008). In particular, the parameterized eddy response to the SAM is maximum with a time lag of $2 \mathrm{yr}$, consistent with the eddy-resolving simulations of Meredith and Hogg (2006) and Screen et al. (2009).
The positive Ekman pumping south of $45^{\circ} \mathrm{S}$ associated with a positive SAM phase creates a divergence of water masses around Antarctica that increases the isopycnals' slope in the ACC, leading to a rapid intensification of its zonal transport, consistent with Sen Gupta and England (2006), Hall and Visbeck (2002), and Meredith et al. (2004). The Ekman pumping also generates an equivalent barotropic dipolar circulation cell in the MOC in the Southern Hemisphere. One year after a positive SAM phase, this circulation cell reverses, leading in the South Atlantic to an increase in the incoming NADW at $30^{\circ} \mathrm{S}$. In the model, the fast response of the Southern Ocean to the SAM is very zonally symmetric. However, the observations suggest more dependence on longitude. Using hydrographic and Argo profiles, Sallée et al. (2008) found that the ACC fronts could be displaced either poleward or equatorward, or simply intensified by the SAM, depending on the ocean basins. The discrepancy results from the SAM pattern being much too zonal in the IPSL CM4 model.

The AMOC was shown to intensify about 8 yr after a positive SAM, although the signal is weak, typically reaching only $0.15 \mathrm{~Sv}$. It results from a correlation between the SAM and wind stress in the northern North Atlantic atmosphere, which was shown to reflect both a SAM-forced atmospheric teleconnection to the northern North Atlantic and a hemispherically symmetric influence of ENSO. Both mechanisms lead to anomalous salinity advection toward the main area of deep convection in the model, which progressively erodes the vertical stratification after a positive SAM, enhances the deep convection, and then accelerates the AMOC. The observations also suggest interhemispheric links related to ENSO (Seager et al. 2003), albeit less pronounced in the northern North Atlantic, but we found no significant correlations between the SAM and the North Atlantic SLP in the reanalysis. Although this may be due to the more limited sample, the interhemispheric teleconnections are likely to be too strong in the model. Hence, the link between the AMOC and the SAM at the decadal scale may be model specific and requires further investigation.

At the multidecadal scale, the SAM alters the AMOC through salinity advection from the Southern Hemisphere into the northern North Atlantic. A positive phase of the SAM creates positive salinity anomalies that enter in the Atlantic basin from the Drake Passage and, more importantly, from the Indian Ocean by Agulhas leakage. These anomalies are slowly advected northward, crossing the equator and spreading in the northern subtropics in about 20 yr. Although we could not trace their circulation further, we showed some evidence based on Lagrangian tracers that they circulate and subduct in the subtropical gyre, and are then advected northward along the North Atlantic Current, reaching the northern North Atlantic 
about $65 \mathrm{yr}$ after a positive SAM. This enhances the deep convection, so that the AMOC is intensified $70 \mathrm{yr}$ after a positive SAM. A deceleration of the AMOC is found $20 \mathrm{yr}$ later. It was shown that this phase reversal is due to the same mechanism, as negative salinity anomalies coming from the Indian and Pacific basin enter in the Atlantic basin about $20 \mathrm{yr}$ after a positive SAM. This freshening was generated earlier by SAM-driven anomalous advection in the Pacific and the Indian basins and then advected into the Atlantic basin. Note that these AMOC changes are weak, typically reaching $0.2 \mathrm{~Sv}$, but that typical lowfrequency fluctuations are only 4 times larger.

The spreading of oceanic anomalies from the Southern Ocean to the northern North Atlantic has been observed in hosing experiments using climate models (Seidov et al. 2005; Stouffer et al. 2007; Swingedouw et al. 2008). In sensitivity experiments where freshwater was added south of $60^{\circ} \mathrm{S}$ for $100 \mathrm{yr}$, Swingedouw et al. (2008) found that one of the main processes affecting the response of the AMOC was the spread of salinity anomalies from the Southern Ocean toward the North Atlantic convection sites, where they weakened the production of deep water and reduced the AMOC in about $50 \mathrm{yr}$. This time scale is broadly consistent with the time lag found here.

On the centennial time scale, the AMOC seems to be lagging the SAM forcing by a decade or two, with a stronger AMOC corresponding to a positive SAM phase. This is consistent with the steady-state simulation of Toggweiler and Samuels (1995), Sijp and England (2009), and others, supporting that stronger westerlies lead to a stronger AMOC. On the other hand, no relation to the AMOC or the SAM could be found for the strong centennial fluctuations undergone by the ACC in the model. Clearly, much longer simulations are needed to assess the processes controlling the low-frequency response of the World Ocean to the variability of the SAM. This would be of much interest, since observations and models indicate a positive trend in the SAM index over the past few decades and predict its continuation in the twentyfirst century (Marshall 2003; Yin 2005). As a positive SAM should enhance the Atlantic Overturning circulation, it could mitigate the expected decrease of the AMOC in global warming conditions.

Acknowledgments. We thank G. Madec for helpful discussions, R. Msadek, C. Cassou, and F. D'Andréa for useful comments, and Bruno Blanke for making available the Lagragian tool and helping us to use it. We also thank the reviewers, whose insightful comments greatly improved the paper. The research leading to these results has received funding from the European Community's Seventh Framework Programme (FP7/2007-2013) under Grant Agreement GA212643 (THOR: "Thermohaline
Overturning_at Risk?," 2008-2012). CF was supported in part by the Institut Universitaire de France.

\section{APPENDIX A}

\section{Multiple Linear Regression}

Our multiple linear regression model assumes that a zero-mean variable $y(t)$ can be expressed as an error term plus a linear combination of three other zero-mean variables $\left[x_{1}(t), x_{2}(t), x_{3}(t)\right]$, that is,

$$
y(t)=\sum_{i=1}^{3} a_{i} x_{i}(t)+\epsilon(t),
$$

where $\epsilon(t)$ is the error term, also called noise, and the $a_{i}$ are the regression coefficients. Let $\mathbf{A}$ be the vector column of these coefficients, $\mathbf{X}$ the matrix whose the element at the $i$ th row and jth column is $x_{j}(t=i)$, and $\mathbf{Y}=[y(t=i)]_{i=1 \ldots t}$. The regression coefficients are determined by an ordinary least squares estimation:

$$
\mathbf{A}=\left(\mathbf{X X}^{\mathrm{T}}\right)^{-1} \mathbf{X}^{\mathrm{T}} \mathbf{Y},
$$

where the index $\mathrm{T}$ denotes transpose. This is equivalent to an orthogonal projection of the variable $y$ onto the space made of the $\left\{x_{j}\right\}_{j=1 . .3}$ vectors. Statistical significance is tested on each regression coefficient by a Student's $t$ test. For more details, see von Storch and Zwiers (1999).

\section{APPENDIX B}

\section{Removing ENSO}

The ENSO signal is well characterized by the first two EOFs and principal components (PCs) of the SST in the tropical Pacific between $15^{\circ} \mathrm{S}$ and $15^{\circ} \mathrm{N}$. In the model, the first PC is highly correlated with the ENSO-3.4 index ( $r=$ 0.99 ) and the two PC have a spectral peak at a period of 3 yr. To subtract the ENSO signal from the atmospheric fields, we use a linear regression onto the two PCs, assuming a fast atmospheric response. For monthly anomalies, a regression with one or two months' lag gives very similar results. Removing the ENSO signal from oceanic data was not attempted, as the ocean acts as an integrator of the ENSO forcing-removing its influence would require a more sophisticated model of the response of the ocean.

\section{REFERENCES}

Biastoch, A., C. W. Böning, F. U. Schwarzkopf, and J. R. E. Lutjeharms, 2009: Increase in Agulhas leakage due to poleward shift of Southern Hemisphere westerlies. Nature, 462 , 495-499. 
Blanke, B., and S. Raynaud, 1997: Kinematics of the Pacific Equatorial Undercurrent: An Eulerian and Lagrangian approach from GCM results. J. Phys. Oceanogr., 27, 1038-1053.

Böning, C. W., A. Dispert, M. Visbeck, S. R. Rintoul, and F. U. Schwarzkopf, 2008: The response of the Antarctic Circumpolar Current to recent climate change. Nat. Geosci., 1, 864-869.

Bretherton, C. S., M. Widmann, V. P. Dynmnikov, J. M. Wallace, and I. Bladé, 1999: The effective number of spatial degrees of freedom of a time-varying field. J. Climate, 12, 1990-2009.

Brönnimann, S., 2007: Impact of El Niño-Southern Oscillation on European climate. Rev. Geophys., 45, RG3003, doi:10.1029/ 2006RG000199.

Cunningham, S. A., S. G. Alderson, B. A. King, and M. A. Brandon, 2003: Transport and variability of the Antarctic Circumpolar Current in Drake Passage. J. Geophys. Res., 108, 8084, doi:10.1029/2001JC001147.

Delworth, T., S. Manabe, and R. J. Stouffer, 1993: Interdecadal variations of the thermohaline circulation in a coupled oceanatmosphere model. J. Climate, 6, 1993-2011.

Deshayes, J., and C. Frankignoul, 2008: Simulated variability of the circulation in the North Atlantic from 1953 to 2003. J. Climate, 21, 4919-4933.

Dong, B., and R. T. Sutton, 2005: Mechanism of interdecadal thermohaline circulation variability in a coupled oceanatmosphere GCM. J. Climate, 18, 1117-1135.

Eden, C., and J. Willebrand, 2001: Mechanism of interannual to decadal variability of the North Atlantic circulation. J. Climate, 14, 2266-2280.

Fichefet, T., and A. M. Morales-Maqueda, 1999: Modelling the influence of snow accumulation and snow-ice formation on the seasonal cycle of the Antarctic sea-ice cover. Climate Dyn., 15, 251-268.

Friocourt, Y., S. Drijfhout, B. Blanke, and S. Speich, 2005: Water mass export from Drake Passage to the Atlantic, Indian, and Pacific Oceans: A Lagrangian model analysis. J. Phys. Oceanogr., 35, 1206-1222.

Ganachaud, A., and C. Wunsch, 2000: Improved estimates of global ocean circulation, heat transport and mixing from hydrographic data. Nature, 408, 453-457.

Gent, P. R., and J. C. McWilliams, 1990: Isopycnal mixing in ocean circulation models. J. Phys. Oceanogr., 20, 150-155.

Gnanadesikan, A., and R. W. Hallberg, 2000: On the relationship of the Circumpolar Current to Southern Hemisphere winds in coarseresolution ocean models. J. Phys. Oceanogr., 30, 2013-2034.

Gregory, J. M., and Coauthors, 2005: A model intercomparison of changes in the Atlantic thermohaline circulation in response to increasing atmospheric $\mathrm{CO}_{2}$ concentration. Geophys. Res. Lett., 32, L12703, doi:10.1029/2005GL023209.

Hall, A., and M. Visbeck, 2002: Synchronous variability in the Southern Hemisphere atmosphere, sea ice, and ocean resulting from the annular mode. J. Climate, 15, 3043-3057.

Hourdin, F., and Coauthors, 2006: The LMDZ4 general circulation model: Climate performance and sensitivity to parametrized physics with emphasis on tropical convection. Climate Dyn., 27, 787-813.

Hughes, C. W., P. L. Woodworth, M. P. Meredith, V. Stepanov, T. Whitworth, and A. R. Pyne, 2003: Coherence of Antarctic sea levels, Southern Hemisphere Annular Mode, and flow through Drake Passage. Geophys. Res. Lett., 30, 1464, doi:10.1029/ 2003GL017240.

Iudicone, D., G. Madec, B. Blanke, and S. Speich, 2008: The role of Southern Ocean surface forcings and mixing in the global conveyor. J. Phys. Oceanogr., 38, 1377-1400.
Kalnay, E., and Coauthors, 1996: The NCEP/NCAR 40-Year Reanalysis Project. Bull. Amer. Meteor. Soc., 77, 437-471.

Krinner, G., and Coauthors, 2005: A dynamic global vegetation model for studies of the coupled atmosphere-biosphere system. Global Biogeochem. Cycles, 19, GB1015, doi:10.1029/ 2003GB002199.

Liu, Z., and M. Alexander, 2007: Atmospheric bridge, oceanic tunnel, and global climatic teleconnections. Rev. Geophys., $\mathbf{4 5}$, RG2005, doi:10.1029/2005RG000172.

Madec, G., P. Delecluse, M. Imbard, and C. Lévy, 1998: OPA Version 8.1 Ocean General Circulation Model reference manual. LODYC/IPSL Tech Rep. 11, 91 pp.

Marshall, G. J., 2003: Trends in the southern annular mode from observations and reanalyses. J. Climate, 16, 4134-4143.

Marshall, J., and T. Radko, 2006: A model of the upper branch of the meridional overturning of the Southern Ocean. Prog. Oceanogr., 70, 331-345.

Marti, O., and Coauthors, 2010: Key features of the IPSL ocean atmosphere model and its sensitivity to atmospheric resolution. Climate Dyn., 34, 1-26.

Meredith, M. P., and A. M. Hogg, 2006: Circumpolar response of Southern Ocean eddy activity to a change in the southern annular mode. Geophys. Res. Lett., 33, L16608, doi:10.1029/ 2006GL026499.

_ P. L. Woodworth, C. W. Hughes, and V. Stepanov, 2004: Changes in the ocean transport through Drake Passage during the 1980s and 1990s, forced by changes in the southern annular mode. Geophys. Res. Lett., 31, L21305, doi:10.1029/ 2004GL021169.

Mignot, J., and C. Frankignoul, 2005: The variability of the Atlantic meridional overturning circulation, the North Atlantic Oscillation, and the El Niño-Southern Oscillation in the Bergen Climate Model. J. Climate, 18, 2361-2375.

$\longrightarrow$, and —, 2009: Local and remote impacts of a tropical Atlantic salinity anomaly. Climate Dyn., 35, 1133-1147. doi:10.1007/ s00382-009-0621-9.

Msadek, R., and C. Frankignoul, 2009: Atlantic multidecadal oceanic variability and its influence on the atmosphere in a climate model. Climate Dyn., 33, 45-62.

Munk, W. H., and E. Palmen, 1951: Note on the dynamics of the Antarctic Circumpolar Current. Tellus, 3, 53-55.

Olbers, D., D. Borowski, C. Völker, and J.-O. Wölff, 2004: The dynamical balance, transport and circulation of the Antarctic Circumpolar Current. Antarct. Sci., 16, 439-470.

Rayner, N. A., D. E. Parker, E. B. Horton, C. K. Folland, L. V. Alexander, D. P. Rowell, E. C. Kent, and A. Kaplan, 2003: Global analyses of sea surface temperature, sea ice, and night marine air temperature since the late nineteenth century. J. Geophys. Res., 108, 4407, doi:10.1029/ 2002JD002670.

Russell, J. L., R. J. Stouffer, and K. W. Dixon, 2006: Intercomparison of the Southern Ocean circulations in IPCC coupled model control simulations. J. Climate, 19, 4560-4575.

Sallée, J. B., K. Speer, and R. Morrow, 2008: Response of the Antarctic Circumpolar Current to atmospheric variability. J. Climate, 21, 3020-3039.

Screen, J. A., N. P. Gillett, D. P. Stevens, G. J. Marshall, and H. K. Roscoe, 2009: The role of eddies in the Southern Ocean temperature response to the southern annular mode. J. Climate, 22, 806-818.

Seager, R., N. Harnik, Y. Kushnir, W. Robinson, and J. Miller, 2003: Mechanisms of hemispherically symmetric climate variability. J. Climate, 16, 2960-2978. 
Seidov, D., R. J. Stouffer, and B. J. Haupt, 2005: Is there a simple bi-polar ocean seesaw? Global Planet. Change, 49, 19-27.

Sen Gupta, A., and M. H. England, 2006: Coupled oceanatmosphere-ice response to variations in the southern annular mode. J. Climate, 19, 4457-4486.

Sijp, W. P., and M. H. England, 2009: Southern Hemisphere westerly wind control over the ocean's thermohaline circulation. J. Climate, 22, 1277-1286.

Speich, S., B. Blanke, and G. Madec, 2001: Warm and cold water routes of an O.G.C.M. thermohaline conveyor belt. Geophys. Res. Lett., 28, 311-314.

Stommel, H., 1957: A survey of ocean current theory. Deep-Sea Res., 4, 149-184.

Stouffer, R., D. Seidov, and B. J. Haupt, 2007: Climate response to external sources of freshwater: North Atlantic versus the Southern Ocean. J. Climate, 20, 436-448.

Swingedouw, D., T. Fichefet, H. Goose, and M. F. Loutre, 2008: Impact of transient freshwater releases in the Southern Ocean on the AMOC and climate. Climate Dyn., 33, 365-381.

Talley, L. D., 2003: Shallow, intermediate, and deep overturning components of the global heat budget. J. Phys. Oceanogr., 33, 530-560.

Thompson, D. W. J., and J. M. Wallace, 2000: Annular mode in the extratropical circulation. Part I: Month-to-month variability. J. Climate, 13, 1000-1016.

, and D. J. Lorenz, 2004: The signature of the annular modes in the tropical troposphere. J. Climate, 17, 4330-4342.
Toggweiler, J. R., and B. Samuels, 1995: Effect of Drake Passage on the global thermohaline circulation. Deep-Sea Res. I, 42, 477-500.

_ , and J. Russell, 2008: Ocean circulation in a warming climate. Nature, 451, 286-288.

Treguier, A. M., M. H. England, S. R. Rintoul, G. Madec, J. Le Sommer, and J.-M. Molines, 2007: Southern Ocean overturning across streamlines in a eddying simulation of the Antarctic Circumpolar Current. Ocean Sci., 3, 491-507.

_ - J. Le Sommer, J. M. Molines, and B. de Cuevas, 2010: Response of the Southern Ocean to the southern annular mode: Interannual variability and multidecadal trend. J. Phys. Oceanogr., 40, 1659-1668.

Valcke, S., Ed., 2006: OASIS3 user guide. PRISM-Support Initiative Tech. Rep. 3, 64 pp. [Available online at http://www.prism. enes.org/Publications/Reports/oasis3_UserGuide_T3.pdf.]

von Storch, H., and F. W. Zwiers, 1999: Statistical Analysis in Climate Research. Cambridge University Press, 494 pp.

Whitworth, T., III, 1983: Monitoring the transport of the Antarctic Circumpolar Current at Drake Passage. J. Phys. Oceanogr., 13, 2045-2057.

_ Circumpolar Current from bottom pressure measurements. J. Phys. Oceanogr., 15, 810-816.

Yin, J. H., 2005: A consistent poleward shift of the storm tracks in the simulations of 21st century climate. Geophys. Res. Lett., 32, L18701, doi:10.1029/2005GL023684. 